\title{
ENVOLVIMENTO DE AGRICULTORES NO PROCESSO SELETIVO DE NOVAS LINHAGENS DE FEIJOEIRO
}

\author{
Involving farmers in the selection of new common bean lines
}

\author{
Marcus Reis Sena ${ }^{1}$, Ângela de Fátima Barbosa Abreu², Magno Antonio Patto Ramalhoª , Adriano Teodoro Bruzi ${ }^{1}$
}

\begin{abstract}
RESUMO
Neste trabalho, objetivou-se o envolvimento de agricultores na seleção de novas linhagens de feijoeiro. Foram conduzidos 10 experimentos onde foram avaliadas nove linhagens melhoradas de feijão, juntamente com a cultivar BRSMG Talismã, em propriedades agrícolas com tradição na cultura do feijoeiro. O delineamento experimental foi o de blocos casualizados com três repetições e as parcelas de 10 linhas de $5 \mathrm{~m}$. Foram avaliadas, a severidade de mancha-angular, produtividade e solicitada aos agricultores a avaliação do tipo de grão. A linhagem OP-S-30 foi a que apresentou maior produtividade média nos 10 ambientes avaliados, tolerância a mancha angular e tipo de grão com boa aceitação de acordo com a opinião dos agricultores. Além dessa linhagem, a OP-S-16 e OP-S-80 também apresentaram desempenho superior. Os resultados obtidos evidenciaram que os agricultores e melhoristas têm muitos objetivos comuns com relação aos fenótipos desejáveis de uma cultivar de feijão para a região.
\end{abstract}

Termos de indexação: Feijão, Phaseolus vulgaris L., melhoramento vegetal, avaliação de linhagens, melhoramento participativo.

\section{ABSTRACT}

This work had the objective of involving the farmers in the selection of new common bean inbred lines. Ten experiments were carried out to evaluate nine inbreed lines and the commercial cultivar BRSMG Talismã in farm conditions of traditional common bean producers. The experimental design was a randomized complete blocks with three replications with plots of 10 rows of $5 \mathrm{~m}$ each. Angular leaf spot severity and yield were evaluated and it was required from farmers to evaluate about the grain type. Inbred line OP-S-30 presented the highest mean grain yield in all environments, angular leaf spot tolerance and grain type with good acceptance according to the farmers. Besides the two inbred lines OP-S-16 and OP-S-80 presented higher performance. The results reinforced that the farmers and breeders really have very common objectives in relation to the desirable phenotypes for a common bean cultivar in the region.

Index terms: Common bean, Phaseolus vulgaris L., plant breeding, lines evaluation, participatory plant breeding.

(Recebido em 5 de junho de 2006 e aprovado em 1 de março de 2007)

\section{INTRODUÇÃO}

Com a cultura do feijoeiro, só no estado de Minas Gerais, existem 295 mil produtores, sendo a maioria familiar, que cultivam pequenas áreas e comercializam o excedente (VIEIRA et al., 2006). Apenas $10 \%$ da área é cultivada com sementes melhoradas, a maioria por grandes empresários rurais. A quase totalidade dos agricultores reutiliza os grãos colhidos como sementes, fato este que contribui não só para obtenção de grãos de pior qualidade, como redução na produtividade. Nesse caso, se houvesse maior uso de sementes de cultivares melhoradas poderia haver uma melhoria no desempenho da cultura no estado.

Nos programas de melhoramento são avaliadas centenas de linhagens, contudo, apenas um pequeno número é registrado como cultivar no Ministério da Agricultura, Pecuária e Abastecimento - MAPA. Para um melhor aproveitamento das linhagens com bom potencial, mas que não chegaram a ser registradas no MAPA, poderse-ia avaliá-las mais intensivamente com a participação dos agricultores que normalmente não adquirem sementes fiscalizadas. Assim, poderiam ser selecionadas aquelas que melhor se adaptassem à agricultura familiar. A participação dos agricultores no processo seletivo tem sido objeto de inúmeras pesquisas (ALMEKINDERS \& ELINGS, 2001; FUKUDA, 2001) e todas elas enfatizam a sua importância na decisão de qual ou quais linhagens poderão ser recomendadas.

Diante do exposto, nesse trabalho, objetivou-se o envolvimento de agricultores com melhoristas no processo seletivo de novas linhagens de feijoeiro, com boa adaptação à agricultura familiar.

\section{MATERIAL E MÉTODOS}

Os experimentos foram conduzidos em 10 ambientes envolvendo propriedades agrícolas nos municípios de

\footnotetext{
Pós-graduandos em Genética e Melhoramento de Plantas - Departamento de Biologia/DBI - Universidade Federal de Lavras/UFLA - Cx. P. 3037 37200-000 - Lavras, MG - mreissena@yahoo.com.br; atbruzi@yahoo.com.br

2Doutora em Genética e Melhoramento de Plantas - Embrapa Arroz e Feijão/UFLA - Departamento de Biologia/DBI - Universidade Federal de Lavras/UFLA Cx. P. 3037 - 37200-000 - Lavras, MG - afbabreu@ufla.br

3outor em Genética e Melhoramento de Plantas - Departamento de Biologia/DBI - Universidade Federal de Lavras/UFLA - Cx. p. 3037 - $37200-000$ magnoapr@ufla.br
} 
Lavras, Alterosa, Alfenas, Cana Verde, Candeias e São Vicente de Minas. Alatitude e longitude variaram de 20 83 'S a $21^{\circ} 67^{\prime} \mathrm{S}$ e de $44^{\circ} 05^{\prime} \mathrm{W}$ a $45^{\circ} 91$ ' $\mathrm{W}$ e a altitude de 840 a $1060 \mathrm{~m}$. Na safra "das águas" 2004/2005 foram conduzidos experimentos em todos os municípios citados e, na safra "da seca" de 2005, em quatro locais; duas propriedades agrícolas do município de Lavras, uma em Cana Verde e outra em Alfenas. As propriedades agrícolas foram escolhidas com o auxilio dos extensionistas da Emater de cada local. Foram selecionadas aquelas com tradição na cultura e cujos produtores demonstraram interesse na condução do trabalho.

Foram avaliadas nove linhagens com grão tipo carioca (cor creme com rajas marrons) e hábito de crescimento entre II a III, sendo provenientes de diferentes ciclos de seleção do programa de melhoramento da UFLA/ Embrapa. Essas linhagens foram escolhidas em função do bom desempenho apresentado nas avaliações realizadas nas estações experimentais, mas que não foram registradas como novas cultivares. Como testemunha foi utilizada a cultivar BRSMG Talismã.

O delineamento experimental foi o de blocos casualizados com três repetições e as parcelas de 10 linhas de $5 \mathrm{~m}$ espaçadas de $0,5 \mathrm{~m}$, colocando-se 15 sementes por metro linear. Como adubação foram empregados $300 \mathrm{~kg}$ ha ${ }^{1}$ da fórmula 8-28-16 de $\mathrm{N}, \mathrm{P}_{2} \mathrm{O}_{5}$ e $\mathrm{K}_{2} \mathrm{O}$ por ocasião da semeadura e, 20 dias após a emergência, $150 \mathrm{~kg} \mathrm{ha}^{-1} \mathrm{de}$ sulfato de amônio em cobertura. Para controle de plantas daninhas foi utilizado o herbicida Robust ${ }^{\circledR}$, na dosagem de 0,5 1/ha. Não foi utilizada irrigação em nenhum experimento.

As características avaliadas foram: severidade de mancha angular com emprego de uma escala de severidade de nove graus proposta pelo CIAT e adaptada por Nietsche (2000), em que 1 indica ausência de doença e 9 plantas severamente atacadas; produtividade de grãos, em kg ha', e tipo de grão, compreendendo aparência, tamanho, cor e formato, avaliado por meio de escala de notas de 1 a 5 , em que a nota 1 foi atribuída aos grãos considerados ótimos e 5 aos ruins.

Os dados da produtividade de grãos e notas para severidade de mancha angular e tipo de grãos (transformadas para a raiz quadrada), foram submetidos à análise de variância, inicialmente, por experimento e posteriormente, foi realizada a análise conjunta conforme Ramalho et al. (2005). Estimou-se o índice de confiança (risco) na adoção de uma linhagem utilizando o método proposto por Annichiarico et al. (1995).

\section{RESULTADOS E DISCUSSÃO}

A precisão experimental, avaliada pelo coeficiente de variação (CV), variou de 9,3\%, experimento de Cana
Verde safra das águas, a 21,8\% em Candeias na mesma safra, com média de $16,9 \%$. Na literatura, é freqüentemente mencionado que uma das restrições do melhoramento participativo é a menor precisão experimental, em consequência da dificuldade de manejo dos experimentos nas propriedades rurais. Essa dificuldade ficou bem evidenciada nesse trabalho, pois em várias situações, o agricultor não dispunha de uma plantadora, de implemento para controle das plantas daninhas e trilhadora de feijão, dificultando o trabalho, mas que não impediu que os experimentos apresentassem precisão semelhante às que têm sido obtidas em experimentos conduzidos nas estações experimentais (SILVA et al., 2002).

A produtividade média dos experimentos variou amplamente. A maior estimativa foi em Cana Verde na safra das águas (3.418 $\left.\mathrm{kg} \mathrm{ha}^{-1}\right)$ e a menor no mesmo local na safra da seca (799 $\mathrm{kg} \mathrm{ha}^{-1}$ ) (Tabela 1). Essa amplitude de variação na produtividade média é ocasionada por alguns fatores. O principal deles foi a precipitação pluvial bem irregular durante o ciclo da cultura nos experimentos da seca. O feijoeiro não exige muita água, contudo é necessário que essa seja bem distribuída durante o ciclo da cultura (SILVEIRA\& STONE, 2004).

Outra diferença marcante entre os ambientes, foi que em Cana Verde, safra, das águas, onde se obteve a maior produtividade média, a área experimental foi anteriormente utilizada com a cultura do café tendo uma maior disponibilidade de nutrientes. A ocorrência de patógenos também contribuiu para a diferença na produtividade média entre os locais. Em Alterosa, safra das águas, muito embora com boas condições de fertilidade, a enorme incidência de mancha angular, causada pelo fungo Pseudocercospora griseola, que ocorreu precocemente, promoveu grande queda de folhas, acelerou o ciclo da cultura e reduziu a produtividade. Esse fato ficou bem evidenciado, pois, a estimativa de correlação linear entre a nota de dano do patógeno e a produtividade foi de $\mathrm{r}=-0,89(\mathrm{P}=0,01)$. A estimativa do coeficiente de regressão linear, $b=-104,51 \mathrm{~kg} \mathrm{ha}^{-1}$, entre a nota de severidade de mancha angular e a produtividade de grãos, mostra que a cada grau de acréscimo na nota da doença houve redução na produtividade média de $104,51 \mathrm{~kg} \mathrm{ha}^{-1}$ (Tabela 2).

Constatou-se que a interação linhagens $\mathrm{x}$ ambientes foi significativa $(\mathrm{P}=0,00)$ indicando que o comportamento das linhagens não foi coincidente nas diferentes propriedades e épocas de semeadura. A ocorrência de interação genótipos x ambientes na cultura do feijoeiro é muito freqüente na literatura (NUNES et al., 2005; PIROLA et al., 2002). Essa é a principal dificuldade encontrada pelos melhoristas na recomendação de cultivares. 
Tabela 1 - Produtividade média de grãos, em kg ha-1 e coeficiente de variação obtidos na avaliação de linhagens de feijão em dez ambientes.

\begin{tabular}{lcccccccccc}
\hline \multicolumn{1}{c}{ Linhagens } & \multicolumn{10}{c}{ Ambientes } \\
\cline { 2 - 11 } & 1 & 2 & 3 & 4 & 5 & 6 & 7 & 8 & 9 & 10 \\
\hline BRSMG Talismã & $3059 \mathrm{a}$ & $993 \mathrm{~b}$ & $1768 \mathrm{~b}$ & $789 \mathrm{~b}$ & $1293 \mathrm{a}$ & $1243 \mathrm{c}$ & $799 \mathrm{a}$ & $1228 \mathrm{a}$ & $1496 \mathrm{~b}$ & $700 \mathrm{~b}$ \\
CIII-R-3-19 & $3479 \mathrm{a}$ & $811 \mathrm{~b}$ & $2175 \mathrm{a}$ & $647 \mathrm{~b}$ & $1063 \mathrm{a}$ & $1403 \mathrm{c}$ & $925 \mathrm{a}$ & $1276 \mathrm{a}$ & $1532 \mathrm{~b}$ & $852 \mathrm{~b}$ \\
OP-S-16 & $3281 \mathrm{a}$ & $1163 \mathrm{a}$ & $1481 \mathrm{~b}$ & $1321 \mathrm{a}$ & $1558 \mathrm{a}$ & $2023 \mathrm{~b}$ & $1049 \mathrm{a}$ & $1251 \mathrm{a}$ & $1880 \mathrm{a}$ & $959 \mathrm{a}$ \\
LH-11 & $3879 \mathrm{a}$ & $910 \mathrm{~b}$ & $2208 \mathrm{a}$ & $499 \mathrm{~b}$ & $1244 \mathrm{a}$ & $1253 \mathrm{c}$ & $924 \mathrm{a}$ & $1265 \mathrm{a}$ & $1467 \mathrm{~b}$ & $688 \mathrm{~b}$ \\
OP-S-30 & $3599 \mathrm{a}$ & $1175 \mathrm{a}$ & $2346 \mathrm{a}$ & $1417 \mathrm{a}$ & $1315 \mathrm{a}$ & $2695 \mathrm{a}$ & $967 \mathrm{a}$ & $1170 \mathrm{a}$ & $2116 \mathrm{a}$ & $632 \mathrm{~b}$ \\
CIII-H-4-12 & $3593 \mathrm{a}$ & $988 \mathrm{~b}$ & $2521 \mathrm{a}$ & $652 \mathrm{~b}$ & $1100 \mathrm{a}$ & $1448 \mathrm{c}$ & $957 \mathrm{a}$ & $1159 \mathrm{a}$ & $1513 \mathrm{~b}$ & $808 \mathrm{~b}$ \\
CIV-151 & $3549 \mathrm{a}$ & $867 \mathrm{~b}$ & $1938 \mathrm{a}$ & $755 \mathrm{~b}$ & $1059 \mathrm{a}$ & $540 \mathrm{~d}$ & $989 \mathrm{a}$ & $1286 \mathrm{a}$ & $1517 \mathrm{~b}$ & $764 \mathrm{~b}$ \\
CIV-449 & $3092 \mathrm{a}$ & $889 \mathrm{~b}$ & $2485 \mathrm{a}$ & $832 \mathrm{~b}$ & $1262 \mathrm{a}$ & $1598 \mathrm{c}$ & $869 \mathrm{a}$ & $1431 \mathrm{a}$ & $1492 \mathrm{~b}$ & $1063 \mathrm{a}$ \\
OP-S-80 & $3282 \mathrm{a}$ & $1083 \mathrm{a}$ & $1298 \mathrm{~b}$ & $1304 \mathrm{~b}$ & $1674 \mathrm{a}$ & $1875 \mathrm{~b}$ & $1008 \mathrm{a}$ & $836 \mathrm{~b}$ & $2024 \mathrm{a}$ & $753 \mathrm{~b}$ \\
OP-S-64 & $3363 \mathrm{a}$ & $938 \mathrm{~b}$ & $1421 \mathrm{~b}$ & $1314 \mathrm{a}$ & $1173 \mathrm{a}$ & $1977 \mathrm{~b}$ & $760 \mathrm{a}$ & $978 \mathrm{~b}$ & $1710 \mathrm{~b}$ & $776 \mathrm{~b}$ \\
\hline Média & 3418 & 981 & 1964 & 953 & 1274 & 1606 & 925 & 1188 & 1675 & 799 \\
CV(\%) & 9,26 & 11,74 & 21,84 & 20,38 & 18,44 & 20,30 & 18,14 & 11,19 & 15,51 & 16,13 \\
$\mathrm{R}^{2}(\%)$ & 47,81 & 58,63 & 43,78 & 46,64 & 76,65 & 79,76 & 50,26 & 28,76 & 46,30 & 59,29 \\
\hline
\end{tabular}

Médias seguidas de mesma letra na coluna pertencem ao mesmo grupo pelo teste de Scott \& Knott (1974) ao nível de 5\% de probabilidade.

Ambientes: 1-Cana Verde (Águas 2004/2005); 2-Lavras (Águas 2004/2005); 3-Candeias (Águas 2004/2005); 4-Alterosa (Águas 2004/2005); 5-Alfenas (Águas 2004/2005); 6-São Vicente de Minas (Águas 2004/2005); 7-Lavras 1 (Seca 2005); 8-Alfenas (Seca 2005); 9-Lavras 2 (Seca 2005); 10-Cana Verde (Seca 2005).

Embora tenha ocorrido interação das linhagens $\mathrm{x}$ ambientes, algumas se destacaram na maioria dos ambientes. Veja por exemplo, o comportamento da linhagem OP-S-30 que esteve no grupo das mais produtivas em nove dos 10 ambientes sendo, portanto, uma linhagem em condição de ser recomendada para a maioria deles (Tabela 1). Essa linhagem é oriunda do cruzamento entre as cultivares Ouro Negro e Pérola. Ambas são bem adaptadas e normalmente com bom desempenho (NUNES et al., 2005; SARTORATO, 2005). As linhagens OP-S-16 e OP-S-80, também provenientes desse cruzamento, embora não tivessem o mesmo desempenho da OP-S-30 também se destacaram na maioria dos ambientes reforçando o que já foi comentado.

É interessante comentar também o desempenho da linhagem LH-11 que foi muito discrepante entre os ambientes. Em Alterosa, onde houve ocorrência acentuada de mancha angular ela ficou no grupo das menos produtivas (Tabela 1). O contrário ocorreu na ausência do patógeno. Por outro lado, linhagens provenientes do cruzamento Ouro Negro x Pérola simbolizadas por OP-S foram as menos infectadas pelo patógeno e, conseqüentemente apresentaram menores notas e as maiores produtividades de grãos. Como a maioria dos agricultores que não adquirem sementes, praticamente não usam defensivo agrícola, a disponibilização de linhagens mais resistentes como as avaliadas nesse trabalho é uma boa opção.

Sob o ponto de vista do agricultor o ideal seria ter uma cultivar que possua menor risco de insucesso. Nesse contexto, a metodologia de Annichiarico et al. (1995), que estima o índice de confiança fornece essa informação. Como no mercado da região, as sementes disponíveis são da cultivar BRSMG Talismã, optou-se por estimar o risco em relação a essa cultivar, ao invés da média do ambiente como empregado por Annichiarico et al. (1995). Observe na Tabela 3, que o maior índice de confiança foi da linhagem OP-S-30. Considerando o nível de $75 \%$ de probabilidade $(\alpha=0,25)$ essa cultivar na pior das hipóteses terá desempenho 20,7\% acima da média da BRSMG Talismã. Ou seja, essa estimativa confirma todos os comentários realizados anteriormente. 
Tabela 2 - Severidade de mancha angular (notas de 1 a 9) em Alterosa e Candeias e notas médias (1 a 5) atribuídas por três agricultores para o tipo de grão de 10 linhagens de feijão.

\begin{tabular}{lccc}
\hline \multirow{2}{*}{ Linhagem } & \multicolumn{2}{c}{ Mancha angular } & Tipo de grão \\
\cline { 2 - 3 } & Alterosa & Candeias & \\
\hline BRSMG Talismã & $9,0 \mathrm{a}$ & $1,7 \mathrm{c}$ & $2,3 \mathrm{~b}(0,0)^{1}$ \\
CIII-R-3-19 & $9,0 \mathrm{a}$ & $2,7 \mathrm{~b}$ & $2,6 \mathrm{~b}(1,3)$ \\
OP-S-16 & $2,7 \mathrm{c}$ & $1,7 \mathrm{c}$ & $1,6 \mathrm{a}(1,0)$ \\
LH-11 & $9,0 \mathrm{a}$ & $4,7 \mathrm{a}$ & $1,6 \mathrm{a}(1,7)$ \\
OP-S-30 & $6,0 \mathrm{~b}$ & $1,0 \mathrm{c}$ & $1,7 \mathrm{a}(0,7)$ \\
CIII-H-4-12 & $9,0 \mathrm{a}$ & $3,6 \mathrm{a}$ & $1,8 \mathrm{a}(1,0)$ \\
CIV-151 & $9,0 \mathrm{a}$ & $2,7 \mathrm{~b}$ & $2,3 \mathrm{~b}(2,0)$ \\
CIV-449 & $8,0 \mathrm{a}$ & $2,0 \mathrm{c}$ & $1,9 \mathrm{a}(0,3)$ \\
OP-S-80 & $3,0 \mathrm{c}$ & $1,0 \mathrm{c}$ & $1,7 \mathrm{a}(1,7)$ \\
OP-S-64 & $2,3 \mathrm{c}$ & $1,3 \mathrm{c}$ & $2,1 \mathrm{~b}(1,3)$ \\
\hline Média & 6,7 & 2,2 & - \\
CV $(\%)$ & 4,59 & 14,56 & 18,97 \\
R MA Produtividade & $-0,888(\mathrm{P}=0,01)$ & $0,546 \mathrm{~ns}$ & - \\
Regressão & $\mathrm{Y}=1653,19-104,51 \mathrm{X}$ & $\mathrm{Y}=1518,54+199,36 \mathrm{X}$ & - \\
$\mathrm{R}^{2}(\%)$ & 78,87 & 27,88 & - \\
\hline
\end{tabular}

${ }^{1}$ Valores entre parênteses representam a amplitude de variação. Médias seguidas de mesma letra na coluna pertencem ao mesmo grupo pelo teste de Scott \& Knott (1974) ao nível de 5\% de probabilidade.

É interessante mencionar o comportamento da linhagem LH-11. O seu índice de confiança foi inferior a $100 \%$, ou seja, ela tem $75 \%$ de probabilidade de apresentar $3,1 \%$ de produtividade abaixo da BRSMG Talismã. Isso ocorre porque essa linhagem é muito suscetível a $P$. griseola. Nos ambientes em que esse patógeno ocorreu sua produtividade média foi reduzida ficando abaixo da BRSMG Talismã, que possui resistência intermediária a esse patógeno (SOUZA et al., 2005). A mesma observação é válida para as linhagens CIV-151 e CIII-R-3-19.

$\mathrm{Na}$ escolha de uma cultivar de feijão, além da produtividade, outros fatores são decisivos. Entre eles, no caso do tipo carioca, a cor, tamanho, brilho e formato dos grãos são fundamentais. Nesse trabalho, procurou-se inicialmente verificar se os agricultores tinham essa percepção. Para isto, a três deles foi solicitado que avaliassem por meio de uma escala de notas, $\mathrm{o}$ aspecto do grão. Esses dados foram submetidos à análise de variância e não se constatou diferença significativa entre os agricultores. Contudo, a interação linhagens $\mathrm{x}$ agricultores foi significativa $(P=0,0008)$, indicando que as notas atribuídas pelos agricultores não foram coincidentes para as diferentes linhagens. Infere-se, em princípio, que a percepção do aspecto dos grãos variou entre os avaliadores. Contudo, chama a atenção que, de um modo geral, os agricultores consideraram todas as linhagens com bom aspecto. É importante salientar que esse caráter é um dos que mais recebe a atenção dos melhoristas da UFLA/ Embrapa nas etapas iniciais do programa. Assim, só foram avaliadas linhagens cujo aspecto dos grãos era aceitável pelos melhoristas. Depreende-se que a percepção dos melhoristas e dos agricultores foram semelhantes.

Uma outra informação interessante a respeito do aspecto dos grão, é que, pelo teste de Scott \& Knott (1974), as linhagens foram classificadas em dois grupos e a linhagem OP-S-30 ficou no grupo das melhores (Tabela 2). A linhagem LH-11, por exemplo, recebeu a nota de menor valor, ou seja, foi considerada como a de melhor tipo de grão pelos agricultores. Isto provavelmente porque essa linhagem apresenta grãos mais claro que as demais, o que é desejável na percepção dos melhoristas e, freqüentemente, observado no processo seletivo.

Durante a condução do trabalho era intenção que os agricultores identificassem as linhagens com melhor 
Tabela 3 - Produtividade média de 10 linhagens de feijoeiro em 10 ambientes com os respectivos índices de confiança [ $\left.{ }_{(\mathrm{i})}\right]$.

\begin{tabular}{ccc}
\hline Linhagem & Média $\left(\mathrm{kg} \mathrm{ha}^{-1}\right)^{1}$ & $\mathrm{I}_{(\mathrm{i})}{ }^{2}$ \\
\hline BRSMG Talismã & $1337 \mathrm{~d}$ & 100,0 \\
CIII-R-3-19 & $1416 \mathrm{c}$ & 99,4 \\
OP-S-16 & $1597 \mathrm{~b}$ & 118,4 \\
LH-11 & $1434 \mathrm{c}$ & 96,9 \\
OP-S-30 & $1743 \mathrm{a}$ & 120,7 \\
CIII-H-4-12 & $1474 \mathrm{c}$ & 102,4 \\
CIV-151 & $1326 \mathrm{~d}$ & 91,1 \\
CIV-449 & $1501 \mathrm{c}$ & 108,4 \\
OP-S-80 & $1514 \mathrm{c}$ & 108,8 \\
OP-S-64 & $1441 \mathrm{c}$ & 101,8 \\
\hline
\end{tabular}

arquitetura da planta. Contudo, para esse caráter ocorreu dificuldade, não tendo sido realizada a avaliação. Em realidade, todas as linhagens possuiam hábito de crescimento indeterminado com guias de crescimento de média a longa de difícil classificação. Contudo, os agricultores têm a percepção de que para certas condições, especialmente semeadura no meio do cafezal, que é muito freqüente na região, linhagens com plantas mais eretas são desejáveis. Esse tipo de caráter já vem sendo objetivo na seleção do feijoeiro no programa de melhoramento da UFLA/Embrapa, no entanto, é necessário intensificar o processo seletivo na direção de plantas ainda mais eretas que as disponíveis (CUNHA et al., 2005).

O contato com agricultores também serviu como motivação para continuar realizando o melhoramento genético do feijoeiro comum. Foi possível ver "in loco" a importância do que é realizado na Universidade e nos Centros de Pesquisa para a sociedade. Além do mais, ficou evidenciado que melhoristas e agricultores têm muitos objetivos comuns no que se refere a uma boa linhagem de feijão.

Ficou bem evidenciado que esse tipo de trabalho exige um maior deslocamento dos pesquisadores para acompanhamento, demandando assim, tempo e maiores recursos. Entretanto, o intercâmbio entre os agricultores e melhoristas propicia uma oportunidade ímpar de se discutirem problemas comuns à cultura e dá enorme vivência aos melhoristas para o estabelecimento das prioridades futuras dos programas de melhoramento em andamento na região.

\section{CONCLUSÕES}

A linhagem OP-S-30 foi a que apresentou maior produtividade média, com boa tolerância à mancha angular e bom tipo de grão. Também se destacaram as linhagens OP-S-16 e OP-S-80.
Os agricultores têm condições de participar no processo seletivo de novas linhagens de feijoeiro.

Agricultores e melhoristas têm muitos objetivos comuns com relação aos fenótipos mancha angular e tipo de grãos desejáveis de uma cultivar de feijoeiro comum para a região.

\section{AGRADECIMENTOS}

À Fundação de Amparo à Pesquisa do Estado e Minas Gerais (FAPEMIG) pelo financiamento do trabalho; ao CNPq e Capes pelas bolsas concedidas; e aos produtores e extensionistas da EMATER pela contribuição na realização dos experimentos.

\section{REFERÊNCIAS BIBLIOGRÁFICAS}

ALMEKINDERS, C. J. M.; ELINGS, A. Collaboration of farmers and breeders: participatory crop improvement in perpective. Euphytica, Wageningen, v. 122, n. 3, p. 425438, 2001.

ANNICHIARICO, P.; BERTOLINI, M.; MAZZINELLI, G. Analysis of genotype $\mathrm{x}$ environment interactions for maize hybrids in Italy. Journal of Genetics and Breeding, Rome, v. 49, n. 1, p. 61-68, Mar. 1995.

CUNHA, W. G. da; RAMALHO, M. A. P.; ABREU, A. de F. B. Selection aiming at upright growth habit common bean with carioca type grains. Crop Breeding and Applied Biotechnology, Londrina, v. 5, p. 379-386, 2005.

FUKUDA, W. M. G. Melhoramento participativo. In: CONGRESSO BRASILEIRO DE MELHORAMENTO DE PLANTAS, 1., 2001, Goiânia. Anais... Goiânia: Embrapa, 2001. 
NIETSCHE, S. Mancha-angular do feijoeiro-comum: variabilidade genética do patógeno e identificação de marcadores moleculares ligados dentificação de raças de Phaeoisariopsis griseola e determinação de à resistência. 2000. 56 f. Tese (Doutorado em Genética e Melhoramento) - Universidade Federal de Viçosa, Viçosa, 2000.

NUNES, J. A. R.; RAMALHO, M. A. P.; ABREU, A. de F. B. Graphical method in studies of adaptability and stability of cultivars. Annual Report of the Bean Improvement Cooperative, Fort Collins, v. 48, p. 182-183, 2005.

PIROLA, L. H.; RAMALHO, M. A. P.; CARNEIRO, J. E. de S.; ABREU, A. de F. B. Natural selection and family x location interaction in the common (dry) bean plant. Genetics and Molecular Biology, Ribeirão Preto, v. 25, n. 3, p. 343-347, 2002.

RAMALHO, M. A. P.; FERREIRA, D. F.; OLIVEIRA, A. C. de. Experimentação em genética e melhoramento de plantas. Lavras: UFLA, 2005. 303 p.

SARTORATO, A. Resistance of andean and mesoamerican common bean genotypes to Phaeoisariopsis griseola.
Annual Report of the Bean Improvement Cooperative, Fort Collins, v. 48, n. 1, p. 88-89, 2005.

SCOTT, A. J.; KNOTT, M. A cluster analysis method for grouping means in the analysis of variance. Biometrics, Washington, v. 30, n. 3, p. 507-512, Sept. 1974.

SILVA, F. B.; BRUZI, A. T.; RAMALHO, M. A. P. Precisão experimental na avaliação de cultivares de feijão. In: CONGRESSO NACIONAL DE PESQUISA DE FEIJÃO, 7., 2002, Viçosa. Anais... Viçosa: UFV, 2002. p. 288-291.

SILVEIRA, P. M.; STONE, L. F. Irrigação. Informe Agropecuário, Belo Horizonte, v. 25, n. 223, p. 74-82, 2004.

SOUZA, T. L. P. O. de; RAGAGNIN, V. A.; MELO, C. L. P. de; ARRUDA, K. M. A.; CARNEIRO, J. E. de S.; MOREIRA, M. A.; BARROS, E. G. de. Phenotypic and molecular characterization of cultivar BRSMG-Talismã regarding the principal common bean pathogens. Crop Breeding and Applied Biotechnology, Londrina, v. 5, n. 2, p. 247-252, Apr./June 2005.

VIEIRA, C.; PAULA JÚNIOR, T. J. de; BORÉM, A. Feijão. 2. ed. atual. e ampl. Viçosa: UFV, 2006. 600 p. 